\title{
CARTOGRAFÍA LEGAL DE LA AUTODETERMINACIÓN INFORMATIVA DIGITAL Un derecho de construcción jurisprudencial
}

\author{
LEGAL CARTOGRAPHY OF DIGITAL INFORMATIVE SELF-DETERMINATION \\ A jurisprudential construction right
}

\author{
Laura Caballero Trenado*
}

\begin{abstract}
RESUMEN: La arquitectura del derecho a la autodeterminación informativa, en su vertiente digital, está ahormada por la doctrina jurisprudencial. Ayuna de una regulación propia hasta la entrada en vigor del Reglamento General de Protección de Datos, el 25 de mayo de 2018, la autodeterminación informativa se ha ido conformando con el cincel de tres órganos jurisdiccionales (el Tribunal de Justicia de la Unión Europea, el Tribunal Constitucional y el Tribunal Supremo) que han ido perfilando y delimitando su contenido y alcance. Desde su reconocimiento por el TJUE en su archiconocida decisión de 13 de mayo de 2014, la evolución que presenta es muy notoria. En la actualidad, una búsqueda en Internet con dos apellidos es suficiente para reconocer este derecho si con ello se lesiona el honor, la intimidad personal o familiar o la propia imagen de su titular. Así lo ha avalado el Tribunal Supremo en la STS 4016/2020, de 27 de noviembre. En este artículo se abordan los hitos jurisprudenciales más relevantes al objeto de bosquejar una cartografía jurídica actual del derecho a la autodeterminación informativa.
\end{abstract}

ABSTRACT: The architecture of the right to informative self-determination, in its digital aspect, is shaped by jurisprudential doctrine. Fasting of its own regulation until the entry into force of the General Data Protection Regulation, on May 25, 2018, digital informational selfdetermination has been conformed to the chisel of three jurisdictional bodies (the Court of Justice of the European Union, the Constitutional Court and the Supreme Court) that have been shaping and defining their content and scope. The evolution of this right since its recognition by the CJEU in its well-known Decision of May 13, 2014 is very relevant. Currently, a search on the Internet with two surnames is sufficient to recognize this right if it damages the honor, personal or family privacy or the image of its holder. This has been endorsed by the Supreme Court in STS 16244/2020, of November 27. This article addresses the most relevant jurisprudential milestones in order to sketch a current legal cartography of the right to informative self-determination.

PALABRAS CLAVE: Autodeterminación informativa digital, derecho al olvido, derecho a la intimidad personal y familiar, derecho al honor, habeas data.

KEYWORDS: Digital informative self-determination, right to oblivion, right to personal and family privacy, right to honour, habeas data.

Fecha de recepción: 24/01/2021

Fecha de aceptación: 19/03/2021

doi: https://doi.org/10.20318/universitas.2021.6189

*Universidad Internacional de la Rioja. E-mail: laura.caballero@unir.net 


\section{1.- INTRODUCCIÓN}

En su interacción con la libertad de expresión y el corolario de las libertades informativas, el honor o la intimidad a menudo se erigen como cuestiones fronterizas. En el complejo y poliédrico fenómeno de la comunicación, que está envuelto en una dinámica convergente, es preciso aquilatar la prevalencia de unos u otros derechos, en atención al caso concreto.

Pero, aunque la intimidad o el honor son conceptos polisémicos de base, en el ordenamiento jurídico español, ambas son realidades jurídico-positivas incuestionables. $Y$, aunque el marco normativo en el que se entroncan es parco, la protección de la que gozan en los distintos cuerpos legislativos nacional, europeo e internacional es también incontrovertible.

Por lo tanto, aunque la casuística es ingente y son los tribunales los que han completado -en constante y reiterada doctrina jurisprudencial- el contenido de estos derechos, su desarrollo ha seguido una evolución clásica.

No puede afirmarse lo mismo del derecho a la autoafirmación informativa.

En este sentido, el derecho a la autoafirmación informativa (también conocido como derecho al olvido o derecho a la supresión) es un derecho de construcción jurisprudencial que fue alumbrado por el Tribunal de Justicia de la Unión Europea (TJUE) en la célebre sentencia de Google Spain de 2014.

En esencia, la resolución precitada (STJUE de Gran Sala, de 13 de mayo de 2014), que resolvía una cuestión prejudicial planteada por la Audiencia Nacional española mediante auto el 27 de febrero de 2012, establecía dos cuestiones. De un lado, anudaba el tratamiento que realizan los motores de búsqueda a la normativa de protección de datos de la Unión Europea. Y, de otro, estipulaba, bajo ciertas condiciones, que los usuarios tienen derecho a solicitar que los enlaces a sus datos personales no aparezcan en los resultados de una búsqueda en Internet realizada por su nombre. Volveremos sobre esta cuestión más adelante.

Hasta la resolución del alto tribunal europeo, el derecho fundamental a la protección de datos ha permanecido conectado a la intimidad. Así, por ejemplo, en desarrollo del mandato constitucional contenido en el artículo 18.1 de la Constitución Española (Derecho al honor, a la intimidad personal y familiar y a la propia imagen), el legislador promulgó la Ley Orgánica 1/1982, de 24 de mayo, de Protección Civil del Derecho al Honor, a la Intimidad Personal y Familiar, y a la Propia Imagen.

La concepción del habeas data como una parte inescindible del derecho a la intimidad, en su vertiente positiva, se constata en la STC 254/1993, de 20 de julio, en la que el órgano jurisdiccional español se 
pronuncia por primera vez sobre esta cuestión, pero sin aclarar si se trata o no de un derecho fundamental.

Así, la protección que el ordenamiento jurídico otorga a un derecho fundamental está reforzada. En concreto, la Carta Magna española reserva al elenco de derechos fundamentales (del 14 al 29) un conjunto de medidas tuitivas que son muy expeditivas ex artículo 53.2 CE.

Como estado miembro de la Unión Europea, España se encuentra inmersa en un sistema multinivel, de ahí que la normativa comunitaria (principalmente, el Convenio Europeo de Derecho Humanos o el reciente RGPD) actúe de contorno que delimita la acción de los órganos jurisdiccionales nacionales.

Por esta razón, el pronunciamiento del TC de 2018 tiene un efecto limitado. No puede soslayarse, sin embargo, la importancia de la entronización del derecho a la autodeterminación informativa digital a la categoría de derecho fundamental, que cuenta ahora con una protección reforzada. Buena prueba de ello es también la línea continuista que ha seguido el TS en sus decisiones, que han contribuido a robustecer este derecho.

\section{2.- METODOLOGÍA}

El análisis se realiza en clave jurídica, de ahí que, fundamentalmente se haya realizado una revisión pormenorizada de la jurisprudencia española y comunitaria.

El periodo objeto de análisis se concentra entre los años 2014, momento en que tiene lugar la primera resolución del TJUE y 2020, cuando el TS sentencia que basta una búsqueda en Internet con dos apellidos para reconocer el derecho a la autodeterminación informativa digital, si con ello se produce un menoscabo de los derechos reconocidos ex artículo $18 \mathrm{CE}$.

Sentado que el derecho a la autodeterminación informativa tiene un desarrollo normativo incipiente y la casuística a menudo desborda el marco legal, está justificado acudir a la doctrina jurisprudencial, pues la labor hermenéutica se residencia en los órganos jurisdiccionales españoles y europeos, tarea que resulta imprescindible, pues, para perfilar su definición, delimitación y alcance.

\section{3.- RESULTADOS}

\section{1.- El derecho al olvido digital: reconocimiento de su existencia}

Como se ha mencionado anteriormente, mediante su archiconocida decisión, de 13 de mayo de 2014, el TJUE reconoce por primera vez el derecho al olvido digital. 
En efecto, el alto tribunal europeo, en una controversia que enfrenta a los metabuscadores Google Spain, S.L. y Google Inc., de un lado, y a la Agencia Española de Protección de Datos (en adelante, AEPD) y al ciudadano español Mario Costeja, de otro, resuelve varias cuestiones prejudiciales planteadas por la Audiencia Nacional mediante auto el 27 de febrero de 2012, en la que establece que las personas tienen derecho a solicitar a Google la eliminación de sus datos personales.

El litigio gira en torno a la protección de los usuarios contra la disponibilidad de información relativa a cuestiones de su esfera personal cuando ya ha mediado un tiempo desde su aparición. Y, si bien dicha información pudiera carecer entonces de relevancia, se encuentra, sin embargo, a disposición de cualquier persona a través de los motores de búsqueda.

En apretada síntesis, los hechos del caso son los siguientes. En 1998, el diario español La Vanguardia publicó en su edición impresa una noticia de embargos de inmuebles por una deuda contraída con la Seguridad Social que afectaba al Sr. Costeja.

Varios años después, al introducir en el buscador su nombre y apellidos, éste arrojaba en la primera página de resultados la noticia, por cuanto el periódico había digitalizado parcialmente su hemeroteca y este suceso seguía apareciendo a través de los enlaces. Se da la circunstancia que el asunto estaba ya resuelto y que carecía, por lo tanto, de interés público. Es ésta una cuestión de suma importancia sobre la que volveremos más adelante.

Interesa ahora subrayar que, aunque se trata de una cuestión inter privatos, que en un primer momento se dirige [sin éxito] ante el medio de comunicación, la indefensión ha de alegarse ante la AEPD, un organismo público.

Y así acaecerá. La máxima autoridad competente para conocer del asunto -la AEPD- da la razón al Sr. Costeja, un acicate importante para proseguir en la vía judicial, habida cuenta del carácter vinculante de las resoluciones de este organismo sancionador, además de la presunción de legitimidad y veracidad que se presume a sus actas de comprobación, que actúan de abono natural de la cualidad probatoria que se proyectará ulteriormente y que se unirán a los autos cuando el asunto finalmente se encuentre sub-iudice.

El iter procesal sigue su cursus en la instancia, donde las distintas resoluciones serán recurridas por el buscador de noticias y llegará finalmente a la Audiencia Nacional.

Cabe recordar que en 2012 había una laguna [léase en derecho nacional] sobre la cuestión. Tanto la Ley de Protección de Datos vigente en derecho español como la autoridad competente sobre la materia que se desarrolla por mandato legal en 1999 no habían desarrollado nada sobre el derecho al olvido, ni en su articulado, la primera, ni a través de sus resoluciones, la segunda. 
En este sentido, al estar ayuno el órgano jurisdiccional español de ley nacional aplicable [sucede también cuando puede albergar dudas acerca de qué norma debe aplicar al caso concreto y cómo debe ser interpretada], está obligado a elevar una cuestión prejudicial ante el tribunal europeo.

Y así lo hace. Como se ha apuntado antes, la Audiencia Nacional eleva mediante auto varias cuestiones prejudiciales ante el tribunal de Luxemburgo.

El tribunal español remite nueve cuestiones al órgano judicial europeo, que plantea en tres bloques.

En concreto, en el primero pregunta el órgano español cuál es el ámbito material de la normativa europea. En el segundo, consulta si la actividad del metabuscador debe considerarse como "tratamiento de datos", por cuanto la citada tarea lleva anudada una responsabilidad, una exigencia que entreabre un catálogo de medidas tuitivas (por ejemplo, la anonimización o la seudonimización) encaminadas a proteger los derechos de los interesados. Y, en el tercero, cuestiona si un usuario puede dirigirse de manera directa a Google, con el fin de instar al metabuscador a modificar o cancelar datos indexados.

Tras aclarar la cuestión de en qué consiste la actividad de un motor de búsqueda ("hallar información publicada o puesta en Internet por terceros, indexarla de manera automática, almacenarla temporalmente $y$, por último, ponerla a disposición de los internautas según un orden de preferencia determinado" ${ }^{1}$ ) de la ratio decidendi del alto tribunal europeo se desprende que hay un tratamiento cualitativo de los datos por parte del gestor de un motor de búsqueda, que "recoge" datos que "extrae", "registra" y "organiza" posteriormente en el marco de sus programas de indexación, "conserva" en sus servidores $y$, en su caso, "comunica" y "facilita el acceso" a sus usuarios en forma de listas de resultados de sus búsquedas².

En definitiva, hay una conducta activa de los motores de búsqueda sobre los datos que maneja como resultado de su actividad, perfectamente acoplada en la definición de "tratamiento de datos personales" de la Directiva Europea 95/463.

Es en la difusión donde tal propósito alcanza su cénit. En la actividad de la comunicación, es sin duda el acto de la difusión la cuestión sobre la que se cierne el grueso de la decisión de la actividad jurisdiccional, por cuanto en la difusión confluye el acto volitivo principal de la transmisión: la irradiación, la proyección, la externalización, en suma, del mensaje.

\footnotetext{
${ }^{1}$ Caso 131/12, primera conclusión, STJUE 131/2014, de 13 de mayo [2014].

2 ibíd., vigésimo octava conclusión.

3 Ana Azurmendi, 'Por un derecho al olvido para los europeos: aportaciones jurisprudenciales de la sentencia del tribunal de justicia europeo del caso Google Spain y su recepción por la sentencia de la Audiencia Nacional española, de 29 de diciembre de 2014`, UNED. Revista de Derecho Político, núm. 92, enero-abril, [2015], 283-284.
} 
Por lo anterior, tal actividad puede tener afectación en el derecho a la intimidad de una persona que, en esencia, es lo que el TJUE considera que ha de prevalecer. Más aún, tal y como razona en su conclusión LIII, debe hacerse una interpretación amplia de este derecho fundamental.

Por último, tras aquilatar y ponderar la prevalencia del derecho a la intimidad frente a la libertad de expresión y el derecho a la información, anuda la responsabilidad del gestor de un motor de búsqueda a la cuestión del tratamiento cualitativo de datos personales que son susceptibles de protección 4 .

\section{2.- El derecho reconocido no ampara la construcción de un pasado a medida}

En octubre de 2015, con ocasión de una sentencia de pleno que resuelve un recurso de casación el Tribunal Supremo español se pronuncia sobre el asunto por vez primera tras la resolución europea.

De manera sucinta, el relato fáctico es el siguiente. En instancia debe resolverse una litis que se disputa entre dos ex traficantes que fueron condenados en los años ochenta, como parte actora, y el periódico El País, como demandada.

Y la historia se repite de manera análoga al asunto que dirime un año antes el TJUE (la parte demandante alega que el diario ha indexado una noticia en la que pueden localizarse fácilmente sus datos personales y de la que ha transcurrido mucho tiempo, careciendo de relevancia en el presente).

En esta ocasión, no obstante, los derechos fundamentales que debe ponderar el órgano jurisdiccional español son el honor, de un lado, y la protección de datos, de otro.

Tan amplia es la casuística que aún hoy sigue habiendo cuestiones sobre las que no hay doctrina consolidada (dos sentencias de un mismo órgano jurisdiccional en un mismo sentido). Por ejemplo, sobre la hipotética posibilidad de las personas de derecho público de recurrir en amparo en el caso de una eventual vulneración en su derecho al honor.

Esta dificultad nace del hecho de la subjetividad del intérprete, así como de la variabilidad de las ideas que, en cada momento, prevalecen en la sociedad en lo relativo al concepto de honor. "El contenido del derecho al honor es lábil y fluido, cambiante" -tal y como ha señalado el Tribunal Constitucional- " $y$, en definitiva, como hemos dicho en alguna ocasión, dependiente de las normas, valores e ideas sociales vigentes en cada momento" (STC 185/1989, de 13 de noviembre).

${ }^{4}$ En un razonamiento prolijo del que destacan las conclusiones 80,81 y 99 . Caso 131/12, STJUE 131/2014, de 13 de mayo [2014]. 
Tempranamente, pues, el alto tribunal define una realidad jurídica porosa a la realidad del momento. Sin embargo, en doctrina jurisprudencial constante y reiterada, tanto el TC como el TS han mantenido los requisitos de veracidad y relevancia pública como conditio sine qua non para estimar o desestimar una pretensión de prevalencia de un derecho fundamental contenida en un recurso de amparo o de casación, según el caso.

En el caso que nos ocupa, considera el TS que la exigencia de veracidad en los datos objeto de tratamiento fue vulnerada por El País. Sin embargo, sentado lo anterior, la cuestión nuclear para ponderar la prevalencia de un derecho sobre otro se contiene en el fundamento jurídico tercero:

\begin{abstract}
"El problema no es que el tratamiento de los datos personales sea inveraz, sino que pueda no ser adecuado a la finalidad con la que los datos personales fueron recogidos y tratados inicialmente. El factor tiempo tiene una importancia fundamental en esta cuestión, puesto que el tratamiento de los datos personales debe cumplir con los principios de calidad de datos no solo en el momento en que son recogidos e inicialmente tratados, sino durante todo el tiempo que se produce ese tratamiento. Un tratamiento que inicialmente pudo ser adecuado a la finalidad que lo justificaba puede devenir con el transcurso del tiempo inadecuado para esa finalidad, y el daño que cause en derechos de la personalidad como el honor $[\ldots]^{\prime \prime}$.
\end{abstract}

Así pues, para el tribunal español:

"[...] hay que ponderar el ejercicio de la libertad de información que supone la edición y puesta a disposición del público de hemerotecas digitales en Internet, que otorga un ámbito de protección menos intenso que la publicación de noticias de actualidad, y el respeto a los derechos de la personalidad, fundamentalmente el derecho a la intimidad personal y familiar pero también el derecho al honor cuando la información contenida en la hemeroteca digital afecta negativamente a la reputación del afectado" ${ }^{5}$.

Por lo tanto, según el TS, "los elementos para realizar esta ponderación son el potencial ofensivo que para los derechos de la personalidad tenga la información publicada y el interés público que pueda suponer que esa información aparezca vinculada a los datos personales del afectado"6.

No obstante, "el llamado derecho al olvido digital, que es una concreción en este campo de los derechos derivados de los requisitos de calidad del tratamiento de datos personales, no ampara que cada uno construya un pasado a su medida, obligando a los editores de páginas web o a los gestores de los motores de búsqueda a eliminar el tratamiento de sus datos personales cuando se asocian a hechos que no se consideran positivos"7.

\footnotetext{
${ }^{5}$ STS 545/2015, de 15 de octubre; núm. rec. 2772/2013. Fundamento jurídico sexto.

${ }^{6}$ ibíd., fundamento jurídico sexto, párrafo segundo.

7 ibíd., fundamento jurídico octavo.

Universitas, 2021, $\mathrm{N}^{\circ} 35 /$ pp. 2-27

ISSN 1698-7950 / doi: https://doi.org/10.20318/universitas.2021.6189
} 


\section{3.- Los efectos del paso del tiempo como legitimación del derecho}

La segunda sentencia del Tribunal Supremo sobre el derecho a la autodeterminación informativa digital implica que, a partir de abril de 2016, pueda ya hablarse de doctrina jurisprudencial consolidada, circunstancia que se produce cuando un mismo órgano jurisdiccional emite dos pronunciamientos en un mismo sentido.

Efectivamente, en este caso concreto, el alto tribunal español resuelve una casación en la que se pronuncia sobre el derecho a la información sobre la concesión de indultos y los derechos al honor, a la intimidad y protección de datos personales del indultado, tras acoger en la fundamentación jurídica de su fallo doctrina de su decisión anterior.

Los hechos del caso tienen su origen en una demanda interpuesta en un Juzgado de Barcelona por un individuo (seudonimizado Alfonso) contra el metabuscador Google, el operador de telecomunicaciones Telefónica y el portal de noticias Yahoo.

En 1999, el demandante resultó indultado de una pena privativa de libertad pendiente de cumplimiento, hecho que se publicó en el Boletín Oficial del Estado, tal y como establece la normativa.

El actor dirigió una petición a la referida publicación mediante correo electrónico que fue desestimada. Con posterioridad, se dirigió a través del mismo medio a las compañías demandadas, por cuanto su nombre y sus apellidos aparecían en las primeras páginas de resultados de los buscadores con los que las precitadas empresas operaban. Todas desestimaron sus reclamaciones.

La cuestión se dirime en instancia con resultado insatisfactorio a las pretensiones del demandante hasta llegar al TS, que admite a trámite el recurso de casación y dicta sentencia estimatoria del mismo.

En esta ocasión, el recurso de casación que el órgano jurisdiccional debe sustanciar es mixto, debiendo el alto tribunal dirimir dos cuestiones (una de naturaleza procesal y otra jurídico-material o sustantiva).

En este sentido, el primer asunto versa sobre la legitimación pasiva de la filial española de la empresa titular del buscador Google. No entraremos en la ratio decidendi que del órgano judicial sostiene acerca de la matera procesal, por cuanto no forma parte de la cuestión nuclear de este trabajo.

Tras resolver el problema procesal, el tribunal pasa a resolver el aspecto sustantivo, que en esta sentencia gira en torno a los siguientes puntos: el tratamiento de los datos personales vinculados con la concesión de un indulto en un buscador generalista de Internet y el equilibrio entre el derecho a la información sobre la concesión de indultos y los derechos al honor, intimidad y protección de datos personales del indultado. 
En la necesaria ponderación que el tribunal lleva a cabo entre el derecho a la información y los derechos a la personalidad, tiene en cuenta el potencial ofensivo de la información publicada y el interés público de la noticia.

Así, de un lado, para el órgano jurisdiccional:

\begin{abstract}
"Que la sociedad pueda estar adecuadamente informada sobre los indultos otorgados por el Gobierno a personas condenadas por sentencia firme, la identidad de esas personas y los delitos que habían cometido, responde a un interés público, enlazado con el derecho a la libertad de información y al control de los poderes públicos propio de las sociedades democráticas, que justifica el tratamiento inicial de los datos que supone indexar las páginas web donde tales indultos son publicados y mostrarlos en la página de resultados de un buscador generalista de Internet" 8 .
\end{abstract}

Sentado que la publicación de un indulto contiene una legitimación democrática ( $y$, por esta razón, es obligatoria), el Supremo aclara, acogiendo la tesis planteada por el TJUE en mayo de 2014, que el tratamiento de datos personales vinculados a la aprobación de una conmutación deja de ser lícito una vez transcurrido un plazo razonable desde que se ha concedido el indulto si el afectado ejercita su derecho de oposición:

\begin{abstract}
"Ahora bien, un tratamiento de datos que es lícito inicialmente, por respetar las exigencias de calidad de datos, puede, con el paso del tiempo, dejar de serlo. El factor tiempo tiene una importancia fundamental en esta cuestión, puesto que el tratamiento de los datos personales debe cumplir con los requisitos que determinan su carácter lícito y, en concreto, con los principios de calidad de datos (adecuación, pertinencia, proporcionalidad y exactitud), no solo en el momento en que son recogidos e inicialmente tratados, sino durante todo el tiempo que se produce ese tratamiento. Un tratamiento que inicialmente pudo ser adecuado a la finalidad que lo justificaba puede devenir con el transcurso del tiempo inadecuado para la finalidad con la que los datos personales fueron recogidos y tratados inicialmente, y el daño que cause en derechos de la personalidad como el honor y la intimidad, desproporcionado en relación al derecho que ampara el tratamiento de datos"9.
\end{abstract}

\title{
3.4.- Avances en los contornos del derecho: los datos personales publicados en el registro mercantil operan como límite
}

Cuando se cumplen casi tres años de la primera resolución europea sobre el derecho al olvido, el TJUE dicta una nueva sentencia (STJUE 198/2017, de 9 de marzo; C-406/15) con ocasión de una nueva cuestión prejudicial que se le plantea en la que estipula que debe prevalecer la seguridad jurídica, que se concreta en la necesidad de proteger intereses de terceros en relación con sociedades mercantiles.

\footnotetext{
${ }^{8}$ STS 1280/2016, de 5 de abril; núm. rec. 3269/2014. Fundamento jurídico quinto, apartado noveno.

9 ibíd., fundamento jurídico quinto, apartado décimo.

Universitas, 2021, No $35 /$ pp. 2-27 
Brevemente se expone un resumen fáctico. Un empresario italiano, que había sido administrador único de una sociedad que sería declarada en concurso de acreedores y, posteriormente, liquidada y cancelados finalmente sus asientos en el Registro Mercantil, solicita a la Cámara de Comercio que cancelase, anonimizase o bloquease sus datos personales asociados a la mercantil concursada.

Al parecer, la vinculación a la empresa declarada en concurso le impedía una nueva actividad mercantil consistente en la explotación de inmuebles sin que tuviese relación con la empresa concursada, por lo que en instancia solicitaba, además, una indemnización por los daños y perjuicios irrogados a consecuencia de dicha información publicada.

En instancia sus pretensiones son desestimadas. Las resoluciones serán recurridas hasta la interposición de un recurso de casación, que será admitido por el Tribunal Supremo italiano, órgano judicial que, ante la duda de cómo debe interpretar la normativa europea sobre el derecho de protección de datos, eleva una cuestión prejudicial ante el TJUE.

En esta ocasión, el tribunal europeo debe sustanciar la cuestión prejudicial teniendo en cuenta dos principios. De un lado, el principio de publicidad de los registros de sociedades ${ }^{10}$. De otro, el principio de conservación de datos personales.

Respecto del primero, cabe afirmar que se trata de un principio obligatorio que la ley atribuye ex lege a los registros y que responde a la seguridad jurídica necesaria que debe presidir las relaciones jurídicomercantiles, habida cuenta de la naturaleza compleja de las reglas de los mercados.

$Y$, respecto del segundo, la cuestión se torna difícil. El inconveniente para el tribunal europeo reside en que el corpus normativo aplicable al caso (Directiva 95/46/CE del Parlamento Europeo y del Consejo, de 24 de octubre de 1995) no contempla ningún plazo sobre el periodo de conservación de datos.

Por lo tanto, la cuestión nuclear consiste en dirimir si las autoridades nacionales que tienen competencia en materia de registros deben decidir, pasado un tiempo y a solicitud de las personas afectadas, si anonimizan o bloquean sus datos personales 0 , por el contrario, limitan la publicidad 0 , por ejemplo, restringen los destinatarios potenciales.

La conclusión del TJUE al respecto es muy clara. Debe primar la seguridad jurídica, la lealtad en las transacciones comerciales, el buen funcionamiento del mercado interior y los intereses de terceros en relación con las sociedades mercantiles, pero suaviza este

\footnotetext{
${ }^{10}$ La publicidad registral es un el conjunto de sistemas a través del que se puede obtener información sobre los bienes muebles o inmuebles, permitiendo a terceros acceder a la información contenida en los registros. Es un instrumento de cognoscibilidad legal cuyo fin es otorgar seguridad jurídica, de ahí que los derechos contenidos en los registros sean oponibles con carácter erga omnes, es decir, tienen efectos frente a todos.
} 
planteamiento al remitir a los legisladores nacionales, a los que encarga la tarea de decidir, en situaciones excepcionales, si limitan la conservación de datos personales.

\section{5.- El alcance territorial del derecho}

La importante cuestión del alcance espacial de la legislación europea fue objeto de estudio por parte del TJUE en el caso del Sr. Costeja.

Con ocasión de un litigio entre Google y la Autoridad francesa encargada de la protección de datos -Commission Nationale de I'Informatique et des Libertés (CNIL)-, que dará lugar al Case 507/1711, el órgano jurisdiccional europeo se adentra en la vertiente práctica de la aplicación del derecho.

En este caso, es un órgano constitucional -el Consell d'État francés-, que tiene legitimación para plantear cuestiones prejudiciales, el que eleva a través de este mecanismo incidental al TJUE las preguntas que a continuación se exponen.

En primer término, ¿debe interpretarse el "derecho de retirada", según ha sido consagrado por el Tribunal de Justicia de la Unión Europea en su sentencia de 13 de mayo de 2014 sobre la base de las disposiciones de los artículos 12, letra b), y 14, letra a), de la Directiva de 24 de octubre de 1995, en el sentido de que el gestor de un motor de búsqueda que estima una solicitud de retirada está obligado a efectuar dicha retirada respecto de la totalidad de los nombres de dominio de su motor, de tal manera que los vínculos controvertidos dejen de mostrarse independientemente del lugar desde el que se realice la búsqueda a partir del nombre del solicitante, incluso fuera del ámbito de aplicación territorial de la Directiva de 24 de octubre de 1995 ?

En segundo lugar, en caso de respuesta negativa a esta primera cuestión, ¿debe interpretarse el "derecho de retirada", según ha sido consagrado por el Tribunal de Justicia de la Unión Europea en su sentencia antes citada, en el sentido de que el gestor de un motor de búsqueda que estima una solicitud de retirada solamente está obligado a suprimir los vínculos controvertidos de los resultados obtenidos como consecuencia de una búsqueda realizada a partir del nombre del solicitante en el nombre de dominio correspondiente al estado en el que se considera que se ha efectuado la solicitud o, de manera más general, en los nombres de dominio del motor de búsqueda que corresponden a las extensiones nacionales de dicho motor para el conjunto de los estados miembros de la Unión Europea?

Finalmente, además, como complemento de la obligación mencionada en la segunda cuestión, ¿debe interpretarse el "derecho de retirada", según ha sido consagrado por el Tribunal de Justicia de la

${ }^{11}$ Caso 507/17, STJUE 772/2019, de 24 de septiembre [2017]. 
Unión Europea en su sentencia antes citada, en el sentido de que el gestor de un motor de búsqueda que estima una solicitud de retirada está obligado a suprimir, mediante la técnica denominada de "bloqueo geográfico", desde una dirección IP supuestamente localizada en el Estado de residencia del beneficiario del "derecho de retirada", los resultados controvertidos obtenidos como consecuencia de una búsqueda realizada a partir de su nombre, o incluso, de manera más general, desde una dirección IP supuestamente localizada en uno de los Estados miembros sujetos a la Directiva de 24 de octubre de 1995, y ello independientemente del nombre de dominio utilizado por el internauta que efectúa la búsqueda?

Como fácilmente se comprueba, son todas cuestiones que atañen a presupuestos prácticos de aplicación del derecho.

En el momento en que se dicta la resolución que ahora comentamos ya se ha promulgado la nueva norma (nos referimos al RGPD), que es distinta de la que aplica al litigio principal el TJUE, que introduce importantes modificaciones sobre la cuestión nuclear que se sustancia en este asunto a través de los artículos 3 y 17 . Sucede, sin embargo, que el legislador europeo promulga el citado instrumento normativo en mayo de 2016 pero éste no entra en vigor hasta mayo de 2018.

\section{6.- Nuevo límite al derecho: la condición de personaje público}

El "canon de relevancia pública" de lo expresado o informado no es una cuestión ajena a los órganos jurisdiccionales encargados de ponderar la primacía de los derechos personales contenidos en el artículo constitucional 18.1 en su interacción con la libertad de expresión y las libertades informativas.

Son numerosas las ocasiones en las que tanto el TS como el TC se han pronunciado a propósito de este asunto. De hecho, para el órgano encargado de interpretar la norma fundamental, en principio, son razonables las restricciones que las libertades de expresión e información ocasionen sobre el derecho al honor o la intimidad cuando las opiniones o informaciones tengan interés público (por todas, STC 49/2001, de 26 de febrero):

"Para llevar a cabo la ponderación entre los dos derechos invocados las
circunstancias que deben tenerse en cuenta [...] son el juicio sobre la
relevancia pública del asunto $[\ldots .$.$] y el carácter de personaje público del sujeto$
sobre el que se emite la crítica u opinión $[\ldots]$, especialmente si es o no titular
de un cargo público. Igualmente importa para el enjuiciamiento constitucional
el contexto en el que se producen las manifestaciones enjuiciables (STC
$107 / 1988)$, como una entrevista o intervención oral [...]. De entrada, debe
señalarse que, en el presente caso, las circunstancias en las que se produjeron
las controvertidas declaraciones del señor Mendoza Fontela ponen de
manifiesto la existencia de una colisión entre el derecho a la libertad de
expresión [art. 20.1 a) CE] y el derecho al honor (art. 18.1 CE) [...]. De 
acuerdo con la diferencia que desde la STC 104/1986 hemos establecido entre la amplitud de ejercicio de los dos derechos considerados, la libertad de expresión [art. 20.1 a) CE] dispone de un campo de acción que viene sólo delimitado por la ausencia de expresiones indudablemente injuriosas o sin relación con las ideas u opiniones que se expongan y que resulten innecesarias para su exposición [...]". (Fundamento jurídico sexto).

Y que se difunda a través de un medio de comunicación social, tal y como se recoge en la paradigmática STC 107/1988, de 8 de junio; también recoge esta doctrina la STC 15/1993, de 18 de enero:

\begin{abstract}
"[...] teniendo en cuenta el contexto en que se producen -una entrevista periodística dirigida a la información pública-, su alcance de crítica impersonalizada en la que no se hacen imputaciones de hechos a Jueces singularizados, cuyo honor y dignidad personal no resultan afectadas y el interés público de la materia sobre la cual recae la opinión -el funcionamiento de la Administración de Justicia-, la jurisdicción penal debió entender, de haber realizado una correcta ponderación de los valores en conflicto, que la libertad de expresión se ejercitó en condiciones que, constitucionalmente, le confieren el máximo nivel de eficacia preferente $y$, en consecuencia, que la lesión inferida a la dignidad de clase determinada del Estado encuentra justificación en la protección que merece el ejercicio de dicha libertad, cuando, como ocurre en este caso, no traspasa los límites que se dejan anteriormente establecidos, aunque la opinión emitida merezca los calificativos de acerba, inexacta e injusta". (Fundamento jurídico tercero).
\end{abstract}

"No se puede negar en primer lugar que el hecho objeto de la información tiene relevancia a nivel local, en cuanto que se trata de unas manifestaciones públicas de un concejal del Ayuntamiento que pueden resultar de interés para la opinión pública. Desde este punto de vista es evidente que el hecho puede ser considerado noticioso o noticiable a nivel local y por tanto contenido de la libertad de información [...]. (Fundamento jurídico segundo).

El alcance efectivo del derecho al honor [o a la intimidad personal y familiar] dependerá así, en cada caso, del contexto en el que se produzca la presunta agresión. Es muy relevante, por ejemplo, que la persona concernida por la opinión o información tenga una dimensión pública o que sea afectado por hechos que son objetivamente noticiables.

Con carácter general puede afirmarse que las personas que ejercen funciones públicas, o resultan implicadas en asuntos de relevancia pública, deben soportar un cierto mayor riesgo de injerencia en sus derechos de la personalidad que las personas privadas (SSTC 19/1996, de 12 de febrero y 68/2008, de 23 de junio):

"[...] al encontrarnos ante una lesión de significación pública, haya de ponderarse frente a otros intereses públicos en juego, como es, necesariamente, el derecho a comunicar o recibir libremente información veraz por cualquier medio de difusión [art. 20.1 d) C.E.]. Libertad que, en el presente caso, debe prevalecer en tanto que la información transmitida no sea gratuita o notoriamente infundada y esté referida a asuntos públicos que son del interés general por las materias a que se refieren y por las personas que 
en ellos intervienen, puesto que las personas que ejercen funciones públicas, o resultan implicadas en asuntos de relevancia pública, deben soportar un cierto mayor riesgo de injerencia en sus derechos de la personalidad que las personas privadas[...]". (Fundamento jurídico tercero).

"[...] las personas que ejercen funciones públicas, o resultan implicadas en asuntos de relevancia pública, deben soportar un cierto mayor riesgo de injerencia en sus derechos de la personalidad que las personas privadas. Ello es así porque en la base de toda sociedad democrática está la formación de una opinión pública libre y plural que, en principio y salvo excepcionales limitaciones, puede tener acceso a la información que afecta al funcionamiento de las instituciones públicas". (Fundamento jurídico tercero, apartado c).

Por lo tanto, y aunque en alguna ocasión el TC haya puesto de manifiesto que ello no significa en modo alguno que, en atención a su carácter público, dichas personas queden privadas de ser titulares del derecho al honor que el art. 18.1 CE garantiza (por ejemplo, en la STC $336 / 1993$, de 15 de noviembre; fundamento jurídico quinto, apartado a), el interés público opera como restricción de los derechos contenidos en el citado precepto.

En la ponderación entre el derecho al olvido y el derecho a la libertad informativa, la doctrina consolidada señala tres criterios: "[...] el interés público actualizado, el estudio del contexto en el que se ha difundido la información y la aplicación del principio de proporcionalidad ${ }^{12}$.

En línea continuista con la doctrina jurisprudencial constante, la Sala de lo Civil del TS va un paso más allá de lo expresado en su resolución STS 545/2015, de 15 de octubre $y$, mediante auto (ATS $3168 / 2017$, de 4 abril), desestima dos recursos -uno de casación y otro extraordinario por infracción procesal-, en el que la parte actora alegaba intromisión ilegítima en su derecho a la protección de datos personales, a la intimidad personal y familiar a la imagen y al honor, solicitando la retirada de la información personal de las indexaciones y cachés que hacían referencia a una información que consideraba lesiva para sus intereses.

El resumen de la ratio decidendi se concentra en que no puede exigirse al editor de una página web que por su propia iniciativa depure datos porque ello supondría un sacrificio desproporcionado para la libertad de información, pero sí puede exigirse que dé una respuesta adecuada a los afectados que ejerciten sus derechos de oposición y cancelación al tratamiento de datos ${ }^{13}$.

Obviamos en este caso el relato fáctico por cuanto guarda un paralelismo significativo con los hechos referidos con ocasión del

\footnotetext{
${ }^{12}$ Por ejemplo, Pere Simón, El Reconocimiento del derecho al olvido digital en España y en la UE, ( $1^{\text {a }}$ ed., Wolters Kluwer 2015), 192.

${ }_{13}$ Sandra Gamella, Derecho al honor, intimidad y propia imagen en relación con las nuevas tecnologías (Sepin 2018), 273.
} 
primer pronunciamiento sobre el derecho al olvido digital por parte del TS.

Sí que corresponde un breve comentario sobre la motivación del auto pues, aunque se trata de un Instrumento procesal que en principio tiene menor relevancia que una sentencia (su función principal es dar impulso al proceso), la pertinencia y la justificación en el caso del derecho al olvido digital es relevante, dado que el canon de relevancia pública no es ajeno a los órganos en los que se residencia la labor hermenéutica de dirimir la prevalencia de los derechos fundamentales a la libertad de expresión y de las libertades informativas o, por el contrario, la de los derechos al honor o la intimidad, por ejemplo.

Sí, en cambio, constituye una novedad en el caso del derecho a la supresión, ya que ésta es la primera ocasión en la que el TS se pronuncia al respecto, contribuyendo a delimitar el significado y alcance de éste, al confirmar que no es absoluto, acogiendo, como se ha adelantado, la doctrina contenida en la STS 545/2015, de 15 de octubre, en la que la Sala expresó que el derecho al olvido no ampara que cada uno pueda construir un pasado a su medida.

\section{7.- La entronización de la autodeterminación informativa digital como derecho fundamental}

Mediante la STC 58/2018, de 4 de junio, con motivo de la resolución de un recurso de amparo, el alto tribunal español declara que la búsqueda con nombres propios en hemeroteca digital es una conducta que puede vulnerar ciertos derechos.

Sucintamente, los hechos del caso se remontan a 2011, momento en que los recurrentes en amparo interpusieron demanda de juicio ordinario contra el diario El País por vulneración del derecho al honor, a la intimidad y a la protección de datos de carácter personal (art. 18.1 y 4 CE).

El citado medio de comunicación publicó, en los años ochenta, y en su edición impresa, el desmantelamiento de una red de tráfico de estupefacientes, entre los que se encontraban las personas demandantes de amparo. La noticia, que identificaba a éstas por su nombre, apellidos y profesión. Dos décadas después, El País estableció el acceso gratuito a su hemeroteca digital, contenida en el sitio web www.elpais.com. A partir de ese momento, al introducir los nombres y apellidos de la parte actora, en el principal proveedor de servicios de intermediación de búsqueda en Internet (www.google.com 0 www.google.es), aparecía como primer resultado aquella noticia, y un extracto de la misma. Los demandantes ven desestimadas sus pretensiones en la instancia y deciden recurrir solicitando recabar amparo ante el TC.

La importancia de esta decisión radica, fundamentalmente, en dos cuestiones. De un lado, porque constituye la primera ocasión en que el TC se pronuncia sobre el derecho al olvido. La condición de 
novedad se refuerza, además, en el hecho de que es también la primera ocasión en que se intenta recabar la tutela en vía civil del derecho fundamental a la protección de datos.

Y, de otro, más importante aún, porque el alto tribunal español escinde el derecho a la protección de datos del derecho a la informática. Al conferirle esta autonomía, el TC consagra el derecho a la protección de datos como un derecho fundamental.

De especial interés son los fundamentos jurídicos quinto y sexto. A través de ellos, el TC justifica su tesis en la necesidad de ajustarse a los presupuestos actuales de la información periodística:

\begin{abstract}
"Hoy, la información periodística ya no es sólo la actualidad publicada en la prensa escrita o audiovisual, sino un flujo de datos sobre hechos y personas que circula por cauces no siempre sujetos al control de los propios medios de comunicación, y que nos permite ir hacia atrás en el tiempo haciendo noticiables sucesos que no son actuales. Las anteriores circunstancias exigen ajustar nuestra jurisprudencia sobre la ponderación de los derechos en conflicto". (Fundamento jurídico quinto, párrafo primero in fine).
\end{abstract}

\title{
Por lo tanto:
}

"[...] el derecho al olvido es una vertiente del derecho a la protección de datos personales frente al uso de la informática (art. 18.4 CE), y es también un mecanismo de garantía para la preservación de los derechos a la intimidad y al honor, con los que está íntimamente relacionado, aunque se trate de un derecho autónomo". (Fundamento jurídico quinto, párrafo cuarto).

La escisión del derecho al olvido del derecho fundamental se reconoce a través del siguiente argumento:

\begin{abstract}
"Por tanto, el art. 18.4 CE garantiza un ámbito de protección específico pero también más idóneo que el que podían ofrecer, por sí mismos, los derechos fundamentales mencionados en el apartado 1 del precepto (STC 292/2000, FJ 4), de modo que "la garantía de la vida privada de la persona y de su reputación poseen hoy una dimensión positiva que excede el ámbito propio del derecho fundamental a la intimidad (art. 18.1 CE), y que se traduce en un derecho de control sobre los datos relativos a la propia persona. La llamada "libertad informática" es así derecho a controlar el uso de los mismos datos insertos en un programa informático (habeas data) y comprende, entre otros aspectos, la oposición del ciudadano a que determinados datos personales sean utilizados para fines distintos de aquel legítimo que justificó su obtención" (STC 292/2000, FJ 5 y jurisprudencia allí citada). Por tanto, si las libertades informáticas pueden definirse como derecho fundamental, también lo es, porque se integra entre ellas, el derecho al olvido". (Fundamento jurídico quinto, párrafos séptimo y octavo).
\end{abstract}

De este reconocimiento expreso se derivan importantes consecuencias jurídico-procesales y jurídico-sustantivas.

"Este reconocimiento expreso del derecho al olvido, como facultad inherente al derecho a la protección de datos personales, y por tanto como derecho fundamental, supone la automática aplicación al mismo de la jurisprudencia 
relativa a los límites de los derechos fundamentales. En el FJ 11 de la STC 292/2000, reiterado después en el FJ 4 de la STC 17/2013, de 31 de enero, se estableció que: "[E]l derecho a la protección de datos no es ilimitado, y aunque la Constitución no le imponga expresamente límites específicos, ni remita a los poderes públicos para su determinación como ha hecho con otros derechos fundamentales, no cabe duda de que han de encontrarlos en los restantes derechos fundamentales y bienes jurídicos constitucionalmente protegidos, pues así lo exige el principio de unidad de la Constitución." En este caso, se identifica la libertad de información [art. 20.1 d) CE] como el derecho fundamental que podría actuar como límite del derecho de autodeterminación sobre los propios datos personales". (Fundamento jurídico sexto, primer y segundo párrafos).

Respecto de ambas, cabe recordar la eficacia inter privatos y la protección reforzada de la que gozan los derechos fundamentales (ex art. 53.2 CE), por cuanto tienen acceso al amparo constitucional.

\section{8.- Los proveedores de servicios de motor de búsqueda en internet deben preservar el derecho a la vida privada de las personas}

La madurez jurisprudencial del derecho a la supresión digital comienza a perfilarse con la STS 12/2019, de 11 de enero.

En esta ocasión, la Sala Tercera del Supremo acoge doctrina anterior y establece la prevalencia del artículo 6.4 de la Ley de Protección de Datos de Carácter Personal (Ley Orgánica 15/1999, de 13 de diciembre) vigente en su momento, interpretando que "debe garantizarse la protección del derecho al olvido digital (de conformidad con lo dispuesto en el artículo 18 de la Carta Magna) en aquellos supuestos en que la información que es objeto de difusión, y cuya localización se obtiene a través de motores de búsqueda en internet contenga datos inexactos que afectan en lo sustancial a la esencia de la noticia".

La Sala de lo Contencioso coincide con la Audiencia Nacional cuando en la sentencia recurrida se explica que la exigencia de tutelar el derecho a la información "no puede suponer vaciar de contenido la protección debida del derecho a la intimidad personal y a la propia imagen, así como el derecho a la protección de datos personales, cuando resulten afectados significativamente por la divulgación de noticias en internet".

Por último, para el TS, los proveedores de servicios de motor de búsqueda en Internet ejercen lícitamente su actividad empresarial cuando ponen a disposición del público aplicaciones o herramientas de localización de información sobre personas físicas, circunstancia que está ampara por la libertad de información ex art. 20 CE. Pero, no obstante, "están obligadas a preservar con la misma intensidad el derecho fundamental a la vida privada de las personas afectadas, impidiendo cualquier interferencia que pueda considerarse de ilegítima", por lo que, a partir de esta importante resolución, deberán 
proceder a borrar noticias con datos sustancialmente erróneos o inexactos.

\section{9.- La madurez plena del derecho: una búsqueda en Internet con dos apellidos es suficiente para el reconocimiento de la autodeterminación informativa}

La madurez jurisprudencial del derecho a la supresión digital alcanza su cénit con la STS 4016/2020, de 27 de noviembre.

En efecto, de nuevo la máxima autoridad judicial en esta materia -la Sala Tercera del TS- en un sentido que implica un robustecimiento del derecho a la autodeterminación informativa digital.

En apretada síntesis, los hechos del caso son los siguientes. En 2017, D. Mariano solicita al gestor del metabuscador Bing -Microsoft Corporation- la desindexación de varias urls para las búsquedas realizadas no solo por su nombre completo, sino también por sus dos apellidos. Microsoft accede a la primera petición, pero rechaza la segunda con el argumento de que los dos apellidos no constituyen un identificador inequívoco de una persona.

De igual modo, la AEPD también rechaza la segunda solicitud de D. Mariano, resolución que confirmará la AN al considerar que, conforme a la normativa del Registro Civil, las personas son designadas por su nombre y apellidos.

También para la doctrina, para la que una persona es identificable, cuando su identidad pueda determinarse directa o indirectamente, mediante cualquier información referida a su identidad ${ }^{14}$.

EI TS anula la Sentencia de la AN y estima por lo tanto el recurso de casación interpuesto por D. Mariano.

Al respecto, la Sala sostiene que:

"[...] No resulta coherente, con esa doctrina jurisprudencial, reconocer el derecho al olvido cuando la búsqueda se efectúe a partir del nombre (completo) de una persona y negarlo cuando se efectúa sólo a partir de los dos apellidos de esa persona, pues ello implica no tener en cuenta uno de los principios generales del Derecho de la Unión Europea, que propugna la interpretación uniforme en todos los Estados miembros de la normativa comunitaria europea. No resulta por tanto razonable que la aplicación de la Directiva 95/46/CE esté condicionada, en estos términos, por las diversas legislaciones internas reguladoras del Registro Civil, que determinan cuáles son los elementos identificativos del nombre y el estado civil de los ciudadanos de sus respectivos Estados". (Fundamento jurídico tercero).

En este sentido, considera que teniendo en cuenta la naturaleza del derecho a la supresión, que se reconoce como derecho fundamental en el marco garantista de las libertades informáticas:

${ }^{14}$ Por ejemplo, Elena Gil, Big Data, Privacidad y Protección de Datos, Agencia Española de Protección de Datos [2016], 45 y 46. 
"no cabe interpretar de forma 'tan restrictiva' la referencia al tratamiento de datos de carácter personal relativos al nombre de la 'persona afectada', en el sentido de que operaría sólo en las búsquedas efectuadas a partir del nombre de pila y los dos apellidos de la persona, invocando, para ello, la legislación reguladora del Registro Civil, porque supondría contravenir el espíritu y la finalidad tuitiva de la normativa de la Unión Europea, así como la normativa nacional de protección de datos de carácter personal, que no permiten distinguir, a estos efectos, que la búsqueda se efectúe con base en los apellidos de la persona afectada o del nombre y los dos apellidos de la citada persona". (Fundamento jurídico tercero).

\section{A mayor abundamiento, el alto tribunal considera que:}

"El criterio mantenido en la sentencia impugnada carece de apoyo en la normativa reguladora de la protección de datos personales de la Unión Europea y en la Ley Orgánica 15/1999, de 13 de diciembre, de Protección de Datos de Carácter Personal, pues "supondría restringir, injustificadamente, el derecho, del que es titular la persona afectada, de exigir al gestor de un motor de búsqueda la eliminación de la lista de resultados, obtenida como consecuencia de una búsqueda realizada a partir de nombre con el que se le identifica ordinariamente en la esfera privada o pública, vinculados a páginas webs, que contienen datos e informaciones relativos a su persona, debido a que estos datos e informaciones pueden perjudicarle o desea que se olviden, en determinadas circunstancias, transcurrido un lapso de tiempo que revela su obsolescencia, con la finalidad de salvaguardar su derecho al honor, a la intimidad, así como el derecho a preservar su propia imagen reputacional". (Fundamento jurídico tercero).

Por último, añade que:

"Debe significarse que el Tribunal de instancia no podía ignorar el alcance y significado del tratamiento de datos de carácter personal, en este supuesto, que permite acceder a cualquier usuario de internet a contenidos referidos a diversos aspectos de la vida privada del reclamante, que, potencialmente, puede considerarse una injerencia ilegítima en el derecho a la privacidad, por referirse a datos de carácter privado, sin ninguna transcendencia pública, que carecen de actualidad, como así ha sido reconocido por la propia Agencia Española de Protección de Datos, respecto de las búsquedas realizadas a partir del nombre y los dos apellidos del reclamante". (Fundamento jurídico tercero in fine).

Esta decisión reviste una importancia muy relevante cuyos efectos se proyectan procesal y extraprocesalmente. $Y$ ello está motivado en gran medida por dos cuestiones.

En primer lugar, porque este fallo contribuye a solidificar la doctrina anterior. En este sentido, cabe recordar que dos sentencias emitidas por un mismo órgano jurisprudencial en su sentido análogo se considera doctrina consolidada.

$Y$, seguidamente, porque tras la reforma del recurso de casación cada vez resulta más difícil franquear el pórtico de su admisión, un requisito procesal sine qua non la casación no puede prosperar.

Por lo tanto, justificar el interés casacional es el quid sobre el que se asienta en buena medida la ventura del recurso, lo que prueba que, aunque el derecho a la autodeterminación informativa digital ha alcanzado una madurez jurisprudencial consolidada, está revestido de 
una confección poliédrica que precisa una redefinición constante de su hechura.

\section{4.- DISCUSIÓN}

El derecho a la autodeterminación informativa digital aspira a ser la respuesta jurídica al problema obligando, por ley, a borrar o hacer anónimos los datos personales una vez se ha logrado el objetivo de su tratamiento, concediendo al titular el derecho a oponerse justificadamente al mismo. Se pretende impedir así el perpetuo mantenimiento de algunos datos en Internet altamente sensibles para la dignidad e intimidad de las personas, lo que en la práctica supone, por ejemplo, la eliminación o bloqueo de datos de ficheros de morosos o de listados comerciales, o la cancelación de antecedentes ${ }^{15}$.

Pero, como se ha podido comprobar, la arquitectura del derecho precitado está ahormada por la doctrina jurisprudencial. En parte, ello es debido a que se trata de un derecho cuya configuración jurídica se encuentra en una fase inicial ${ }^{16}$.

En este sentido, cabe recordar que el TC ha tenido una actuación notable en la construcción del derecho fundamental a la protección de datos de carácter personal ${ }^{17}$. Este órgano tiene una doble dimensión frente a este derecho. Casas Baamonde explica esta doble dimensión en los términos siguientes: "[... 1) desde la doctrina del tribunal sobre el derecho a la protección de datos de carácter personal, de análisis obligado porque al tribunal se debe la configuración de tal derecho como fundamental a partir del artículo 18.4 de la Constitución; y 2) desde la práctica del propio Tribunal en la protección de datos de carácter personal, puesto que el Tribunal opera necesariamente con

15 Marina Sancho, Consideraciones procesales del ejercicio del derecho al olvido: examen de jurisprudencia reciente y nuevo marco legal, Madrid, Revista Aranzadi de Derecho y Nuevas Tecnologías núm. 41 [2016] 8.

16 Pablo Fernández, 'El Derecho al Olvido Desde el Ordenamiento Comunitario ', Análise crítica do direito público Iberoamericano, Universidade Lusófana do Porto [2020] 274.

${ }^{17}$ Conviene tener presente que el reconocimiento del derecho a la autodeterminación información informativa como derecho autónomo e independiente del derecho a la intimidad ha sido reconocido por el TC desde el año 1993 -254/1993 (sala primera), de 20 de julio-. Asimismo, también ha señalado este órgano jurisprudencial su carácter instrumental, tal y como reflejan, entre otras, STC 33/1998 (sala primera), de 11 de febrero; STC 35/1998 (sala primera), de 11 de febrero; STC 45/1998 (sala primera), de 24 de febrero; STC 60/1998 (sala segunda), de 16 de marzo; STC $77 / 1998$ (sala primera), de 31 de marzo; SSTC 104/1998, 105/1998 y 106/1998 (sala segunda), de 18 de mayo; SSTC 123/1998, 124/1998, 125/1998 126/1998 (sala segunda), de 15 de junio; STC 158/1998 (sala segunda), de 13 de julio; STC 198/1998 (sala primera), de 13 de octubre; STC 223/1998 (sala primera), de 24 de noviembre; STC 30/1999 (sala primera), de 8 de marzo y SSTC 44/1999 (sala segunda) y 45/1999 (sala segunda), de 22 de marzo. 
datos de carácter personal en las decisiones de resolución de los procesos de su competencia"18.

Ayuno de una regulación propia hasta la entrada en vigor del RGPD, el 25 de mayo de 2018, el derecho a la autodeterminación informativa digital se ha ido conformando con el cincel del órgano jurisdiccional europeo, sobre todo, que ha ido perfilando y delimitando el contenido y el alcance del derecho.

La apuesta por un estándar de protección elevado por parte del órgano jurisdiccional europeo ha quedado patente a través de las SSTJUE, que resuelven los casos $(C-406 / 15)$ y $(C-131 / 12)$.

En España, la constitucionalización ex novo del derecho a través de la STC 58/2018, de 4 de junio, si bien tiene un alcance limitado (no puede olvidarse que estamos en un sistema multinivel), implica automáticamente que adquiere la virtualidad protectora que contiene el artículo $18.4 \mathrm{CE}$.

Ahora bien, una vez expresado el carácter autónomo del derecho, numerosos son los retos y desafíos que se presentan tanto para los potenciales afectados por una intromisión ilegítima en su derecho al olvido digital, como para periodistas, responsables de medios de comunicación, operadores jurídicos, etcétera, incluso, para los propios jueces, que han de enfrentarse a la ardua tarea hermenéutica.

$Y$ ello por cuanto el alumbramiento jurisprudencial del derecho fundamental al olvido digital es muy reciente.

Para la doctrina consolidada, el derecho al olvido tiene sus orígenes en el derecho a la intimidad y en el derecho a la protección de los datos personales, por lo que es evidente que el derecho al olvido proviene y nace de estos derechos ${ }^{19}$.

Se trata de un derecho bifronte: es un derecho autónomo para la protección de datos personales, sean íntimos o públicos, y por tanto con un ámbito de protección más específico e idóneo que el derecho a la intimidad, aunque en ocasiones concrete éste. $Y$ es también un instituto de garantía de otros valores constitucionales (de forma especial intimidad personal y familiar, honor y propia imagen, pero también libertad ideológica, religiosa, sindical, etcétera) ${ }^{20}$.

Envuelto en la dinámica de la comunicación, el derecho al olvido digital es un derecho autónomo, distinto del habeas data, contenido en el 18.4 CE, que a su vez deviene del derecho raíz -la intimidad-, que está configurada en el artículo $20 \mathrm{CE}$.

Ambos artículos -18 y 20 CE- se encuentran en la parte dogmática de la Carta Magna, pero ha de advertirse que de la correcta

\footnotetext{
18 María Emilia Casas, El derecho a la Protección de Datos de carácter personal en la Jurisprudencia del Tribunal Constitucional, Agencia Estatal Boletín Oficial del Estado [2015] 92.

${ }^{19}$ Por todos, vid. María Álvarez, Derecho al olvido en internet: el nuevo paradigma de la privacidad en la era digital (Reus 2015) 26.

${ }^{20}$ Antonio Troncoso, La protección de datos personales. En busca del equilibrio (Tirant Lo Blanch 2010) 320.
} 
interpretación que se haga a partir de la tesis planteada por el TC en la resolución de 4 de junio se derivan importantes consecuencias prácticas.

En concreto, ¿es para el TC el derecho al olvido digital un derecho personalísimo? Si tiene encaje en el derecho fundamental a la intimidad y éste es el derecho-raíz, podría inferirse que sí.

La intimidad, junto al honor y la propia imagen, de un lado, y aquéllos otros relativos a la vida, a la integridad física, al nombre y a la libertad personal, de otro, constituyen el ámbito de protección de los llamados derechos de la personalidad, es decir, aquéllos que tienen por objeto los modos de ser físicos o morales de la persona. Esto es, aquéllos que garantizan el señorío sobre una parte esencial de la propia personalidad.

Así concebidos, los derechos de la personalidad se caracterizan: 1) por ser originarios e innatos; 2) por su carácter de eficacia de derecho absoluto, pudiendo exigirse a cualquiera el respeto de los mismos; 3) por ser derechos personales en la medida en que protegen aspectos de la personalidad, si bien su violación puede dar lugar al resarcimiento económico del daño en vía civil, y 4) por ser derechos irrenunciables, principio éste que puede ofrecer algunas excepciones contempladas en la ley.

El artículo 18.1 CE afirma que "se garantiza el derecho al honor, a la intimidad personal y familiar y a la propia imagen". Este derecho tiene el carácter de fundamental al venir regulado en la Sección 1a, del Capítulo II, bajo la rúbrica "De los derechos fundamentales y de las libertades públicas".

Los apartados 20,30 y 40 del artículo 18 acogen, respectivamente, los principios de la inviolabilidad de domicilio, del secreto de las comunicaciones y de la limitación legal del uso de la informática para garantizar el honor, la intimidad personal y familiar y a la propia imagen de los ciudadanos.

Abundando en esta idea, hasta tal punto se consideran fundamentales que el texto constitucional declara más adelante -en el artículo 20.4- que el respeto de tales derechos supone un límite al ejercicio de las libertades de expresión e información.

El desarrollo legislativo de la tutela constitucional del derecho a la intimidad fue llevado a cabo en virtud de la Ley Orgánica 1/1982, de 5 de mayo. Como su propio nombre indica, esta Ley tiene por objeto el resarcimiento de los daños materiales o morales, perjuicios que, por lo demás, son de especial trascendencia en el caso de las intromisiones o injerencias ilegítimas en el ámbito de este derecho.

A tenor de lo expuesto, la discusión, a partir de la resolución de junio de 2018 se centra en la eficacia horizontal del derecho al olvido digital y su proyección ad intra y ad extra. Cuestiones como, por ejemplo, la titularidad del derecho tanto en personas físicas, como sujetos jurídico-privados $\mathrm{y}$, sobre todo, de naturaleza pública deben perfilarse. 
Y ello por cuanto, reconocida la titularidad del derecho fundamental, se abre, como se ha señalado, un catálogo de medidas de protección jurídico-procesales y de derecho sustantivo muy relevantes. A sensu contrario, si no hay un reconocimiento explícito de la citada titularidad, los sujetos quedarían excluidos de la opción de recurrir en amparo, por ejemplo, pues no cumplen con el requisito de la legitimación necesaria para recabar la tutela.

No son pocas, por lo tanto, las cuestiones que están pendientes de matizar y definir en relación al derecho a la autodeterminación informativa digital. Hay mucha enjundia jurídica.

En este sentido, el desafío es titánico. En particular, para los proveedores de servicios y titulares de medios de comunicación, que deberán decidir caso a caso la intensidad del uso tanto del big data como de la inteligencia artificial y, desde luego, del microtargeting.

Para un sector doctrinal, en la era del big data y de la computación ubicua el principio de neutralidad tecnológica adquiere una relevancia muy significativa con respecto a la privacidad, pues implica "[...] contrarrestar el desequilibrio existente entre el usuario de los productos tecnológicos, que no tiene conocimientos específicos, y los responsables de la tecnología, que predisponen los sistemas de tratamiento de datos personales. Si la tecnología no es neutra, es decir, condiciona la autonomía de su destinatario e impone "formas onerosas de ejercer los derechos [...], se convierte en un factor de dominación". El principio de neutralidad está íntimamente conectado con los principios de privacidad desde el diseño y por defecto, ya que lo que se requiere es una mayor responsabilidad en la planificación y el diseño tecnológico para garantizar el derecho a la vida privada de los usuarios de esa tecnología. A través de este principio se trataría de contrarrestar la técnica contraria, tan común en muchos servicios de Internet que consiste en deshabilitar al máximo la privacidad de las aplicaciones por sus titulares. El principio de neutralidad supone, por lo tanto, incluir dentro de las previsiones técnicas una más: la consideración de que esa tecnología debe ser respetuosa con los derechos humanos. [...] Los principios de neutralidad tecnológica y de privacidad desde el diseño responden a una filosofía semejante, pues si bien no está en juego la integridad física o la salud del usuario, sí lo están sus derechos fundamentales y su libertad" 21 .

El tratamiento cualitativo de los datos, la sectorialización de las audiencias y el corolario de segmentación de perfiles son procedimientos que posibilita la tecnología, pero el derecho a la información no puede amparar una barra libre de conductas. Y no sólo porque el derecho a la supresión digital opera ya como un límite de aquél, sino porque en la era de la comunicación digital, la apuesta por

${ }^{21}$ Ana Garriga, Nuevos Retos para la protección de datos personales: en la era del big data y de la computación ubicua (Dykinson 2015) 243 y 244.

Universitas, 2021, $\mathrm{N}^{\circ} 35 /$ pp. 2-27 
un estándar laxo o elevado de protección configurará los parámetros de la sociedad del futuro.

De momento, las espadas están en alto en torno a dos modelos, básicamente. El europeo que, con la introducción de un patrón muy tuitivo - vía RGPD- ha trazado las líneas rojas para los proveedores de servicios de información y el estadounidense, que dejó clara su apuesta por un estándar de protección débil, tras tumbar la Privacy Act (Ley sobre Privacidad) en marzo de 2017 y abrir de este modo la posibilidad de que aquéllos explotasen datos personales.

\section{5.- CONCLUSIONES}

En la dinámica de la comunicación es necesario realizar una ponderación entre el ejercicio de la libertad de información y el respeto a los derechos de la personalidad, fundamentalmente el derecho a la intimidad personal y familiar pero también el derecho al honor cuando la información vulnere la reputación del afectado, para decidir cuál debe prevalecer a la vista de las circunstancias concurrentes.

Los elementos a tener en cuenta para realizar este examen son, de un lado, el potencial ofensivo que para los derechos de la personalidad tenga la información publicada $y$, de otro, el interés público en que esa información aparezca vinculada a los datos personales del afectado en una búsqueda efectuada en un metabuscador.

Un análisis cualitativo de la jurisprudencia consolidada analizada muestra una cartografía del derecho que contiene los siguientes parámetros: los resultados de búsqueda pueden ser bloqueados cuando la información a la que enlacen sea lesiva para el interesado, carezca de relevancia informativa y no afecte a un personaje público.

El derecho a la autodeterminación informativa se ha ido robusteciendo a golpe de sentencias y en la actualidad se reconoce con una mera búsqueda en Internet con dos apellidos.

Pero la cartografía jurídica de este derecho de configuración jurisprudencial contiene también unos caracteres temporales, que quedaron parcialmente fijados en la STJUE 198/2017, de 9 de marzo. En esta resolución recuerda el alto tribunal europeo que los estados miembros están obligados a respetar las normas de Derecho de la Unión en materia de protección de datos personales y, por lo tanto, garantizar su conservación durante un plazo no superior al necesario para los fines para que se recogieron, lo cual enlaza con una posible vulneración de las libertades fundamentales y, en particular, el derecho al respeto de la vida privada, protegida por la Carta de los Derechos Fundamentales de la Unión Europea.

Sin embargo, del repositorio analizado, del que destaca el reconocimiento como del derecho a la autodeterminación informativa como derecho fundamental en la STC 58/2018, de 4 de junio, 
numerosas son aún las cuestiones que están aún pendientes de configurar en torno al alcance de este derecho. Por ejemplo, hasta dónde reside la obligación de los estados miembros de fijar límites temporales y en qué concretos organismos o instituciones deben recaer.

Y, también, aspectos como el alcance de la titularidad del derecho -con el haz de medidas de protección que se abre o se cierra en función de que ésta se reconozca o se deniegue- o del ámbito espacial o material de la normativa, lo que prueba que el derecho a la autodeterminación informativa digital es poroso y está muy vivo.

\section{6.- BIBLIOGRAFÍA}

Ana Azurmendi, 'Por un derecho al olvido para los europeos: aportaciones jurisprudenciales de la sentencia del tribunal de justicia europeo del caso Google Spain y su recepción por la sentencia de la Audiencia Nacional española, de 29 de diciembre de 2014 ', UNED. Revista de Derecho Político, núm. 92, eneroabril [2015].

Ana Garriga, Nuevos Retos para la protección de datos personales: en la era del big data y de la computación ubicua (Dykinson 2015).

Ana Garriga, 'La nueva Ley Orgánica 15/1999, de 13 de diciembre, de Protección de Datos Personales, ¿un cambio de filosofía?', Anales de la Cátedra Francisco Suárez, núm. 34 [2000].

Antonio Troncoso, La protección de datos personales. En busca del equilibrio (Tirant Lo Blanch 2010).

Elena Gil, Big Data, Privacidad y Protección de Datos (Agencia Española de Protección de Datos 2016).

María Álvarez, Derecho al olvido en Internet: el nuevo paradigma de la privacidad en la era digital ( 1 a ed., Reus 2015).

María Emilia Casas, El derecho a la Protección de Datos de carácter personal en la Jurisprudencia del Tribunal Constitucional (Agencia Estatal Boletín Oficial del Estado 2015).

Marina Sancho, 'Consideraciones procesales del ejercicio del derecho al olvido: examen de jurisprudencia reciente y nuevo marco legal', Madrid, Revista Aranzadi de Derecho y Nuevas Tecnologías núm. 41, [2016].

Pablo Fernández, 'El Derecho al Olvido Desde el Ordenamiento Comunitario ', Análise crítica do direito público iberoamericano, Universidade Lusófana do Porto [2020].

Pere Simón, El Reconocimiento del derecho al olvido digital en España $y$ en la UE ( $1^{a}$ ed., Wolters Kluwer 2015).

Sandra Gamella, Derecho al honor, intimidad y propia imagen en relación con las nuevas tecnologías (Sepin 2018). 


\section{1- Legislación}

Constitución Española, de 29 de diciembre de 1978. BOE-A-197831229.

Ley Orgánica 3/2018, de 5 de diciembre, de Protección de Datos Personales y garantía de los derechos digitales.

Reglamento 2016/679 relativo a la protección de las personas físicas en lo que respecta al tratamiento de datos personales y a la libre circulación de estos datos [2016].

Ley Orgánica 1/1982, de 24 de mayo, de Protección Civil del Derecho al Honor, a la Intimidad Personal y Familiar, y a la Propia Imagen.

\section{2- Jurisprudencia}

STS 4016/2020, de 27 de noviembre; núm. rec. 6531/2019

STS 12/2019, de 11 de enero; núm. rec. 5579/2017

STJUE 772/2019, de 24 de septiembre (C-507/17)

STJUE 198/2017, de 9 de marzo (C-406/15)

STC 58/2018, de 4 de junio; núm. rec. 2096/2016

ATS 3168/2017, de 4 abril

STS 1280/2016, de 5 de abril; núm. rec. 3269/2014

STS 545/2015, de 15 de octubre; núm. rec. 2772/2013

STJUE 131/2014, de 13 de mayo (C-131/12)

STC 17/2013, de 31 de enero; núm. rec. 1024/2004

STC 68/2008, de 23 de junio; núm. rec. 5323/2004

STC 49/2001, de 26 de febrero; núm. rec. 881/1997

STC 292/2000, de 30 de noviembre; núm. rec. 1463/2000

STC 19/1996, de 12 de febrero; núm. rec. 3327/1993

STC 15/1993, de 18 de enero; núm. rec. 1681/1989

STC 254/1993, de 20 de julio; núm. rec. 1827/1990

STC 107/1988, de 8 de junio; núm. rec. 57/1987

STC 104/1986, de 17 de julio; núm. rec. 909/1985 